\title{
ANALISIS SEBARAN RADIASI HAMBUR CT SCAN 128 SLICE TERHADAP PEMERIKSAAN CT BRAIN
}

\author{
Purwatiningsi, Hari Eko Prasetio \\ Jurusan Fisika, Fakultas Teknik dan Sains, Universitas Nasional Jakarta \\ Email : purwanti.ningsih85@yahoo.co.id
}

\begin{abstract}
The use of high dose levels in CT Scan Brain produce distribution scattered radiation originating from the patient. This study was conducted to determine the distribution of scattered radiation at a particular point on the CT scan to obtain the curve isodose. Using Experimental Methods researchers conducted measurements of the distribution of the scattering radiation at 128 Slice CT Scan of the Brain CT examination. Thermoluminescent dosimeter (TLD) is used to measure the distribution of scattered radiation and use as a phantom object head. Eksposi parameters used are Brain CT program. Take 19 points to be measured. Using a point distance of 1, 2 meters, 3 meters from the gantry CT Scan. The results showed a minimum value of the distribution of the scattering radiation at the measurement point at a distance of 1 meter, 2 meters. 3 meters is at point $\mathrm{A}$ is the right side of the gantry and a maximum distribution at point $\mathrm{C}$ which is the examination table.
\end{abstract}

Key words: CT Scan, distribution of scattered radiation, isodose curves

\section{PENDAHULUAN}

Perkembangan di Indonesia, CT Scan telah mencapai teknologi dual source 128 slice yang mempunyai keunggulan lebih maju dari teknologi sebelumnya, bahkan beberapa rumah sakit juga sudah memilki teknologi dual source 256 slice. Semakin tingginya teknologi sliceyang dimiliki CT Scan, efek radiasi yang ditimbulkan semakin rendah karena semakin cepatnya waktu dalam penyinaran. Namun penggunaan tingkat dosis radiasi tinggi pada CT Scan menimbullkan distribusi hamburan radiasi yang berasal dari pasien. Menurut (AAPM, 2001)pemeriksaan CT Scan kepala mendapat jumlah dosis radiasi tinggi sebesar $6000 \mathrm{mR}$ dan pemeriksaan CT Scan abdomen dosis radiasi sebesar $4000 \mathrm{mR}$. Area paparan radiasi hambur berbentuk angka delapan yang mana paparan rendah berada di sekitar gantry, sedangkan yang mendapat paparan tinggi berada didekat pasien.

\section{METODE PENELITIAN}

Dalam penelitian ini menggunakan 22 karton dengan tinggi 1 meter untuk tempat menempelkan TLD dan objek phantom akrilik. Pengukuran sebaran radiasi hambur pada pemeriksaan CT brain menggunakan parameter CT Brain sebesar $130 \mathrm{kV}$ dan $254 \mathrm{mAs}$, seperti yang terlihat pada Gambar 1, 2 dan 3. 
Purwatiningsih., \& Prasetio, H., E. 2016. Analisis Sebaran Radiasi Hambur CT Scan 128 Slice terhadap Pemeriksaan CT Brain. Journal of Sainstek 8(1): 50-55

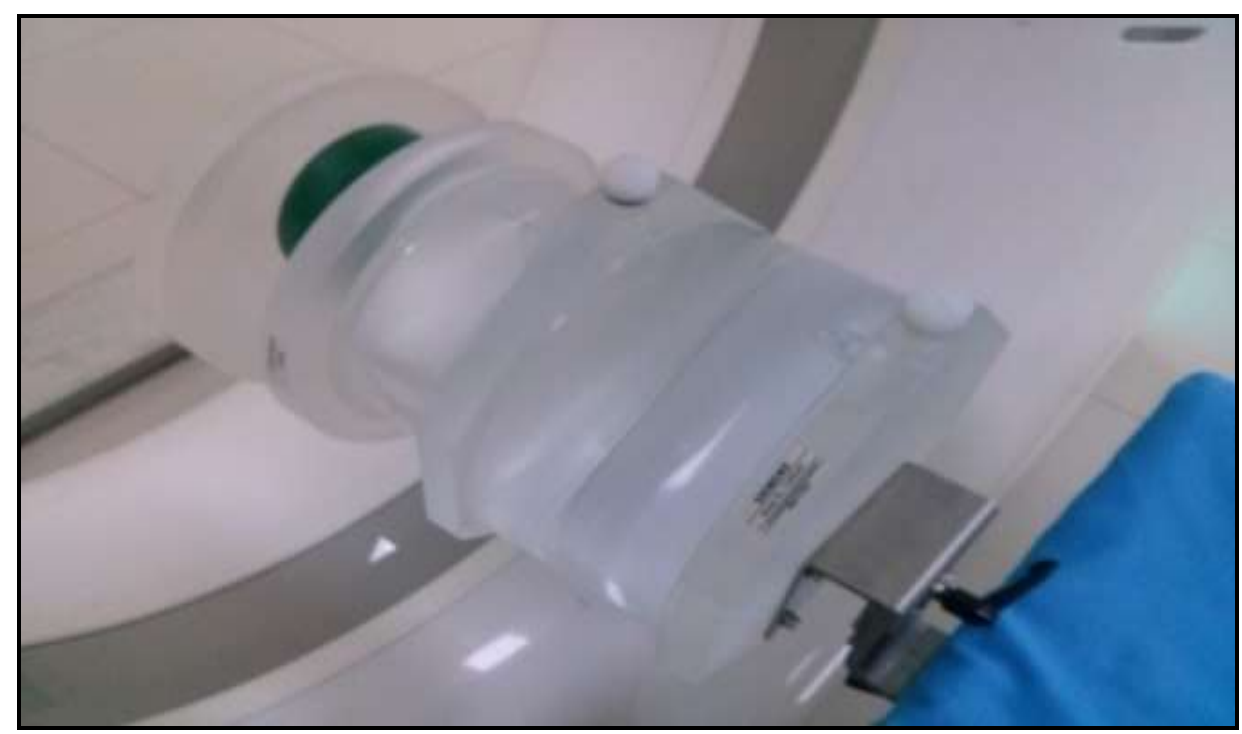

Gambar 1. Phantom Akrilik

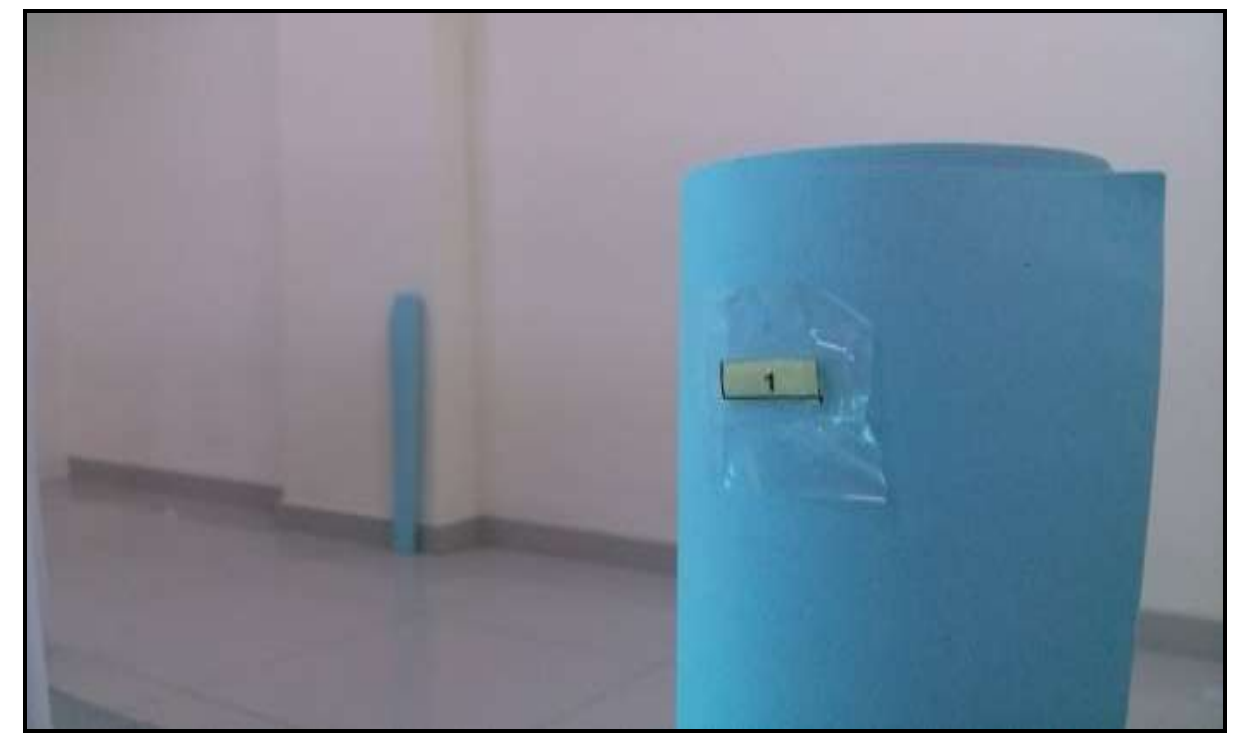

Gambar 2. TLD yang ditempel pada karton berdiri 


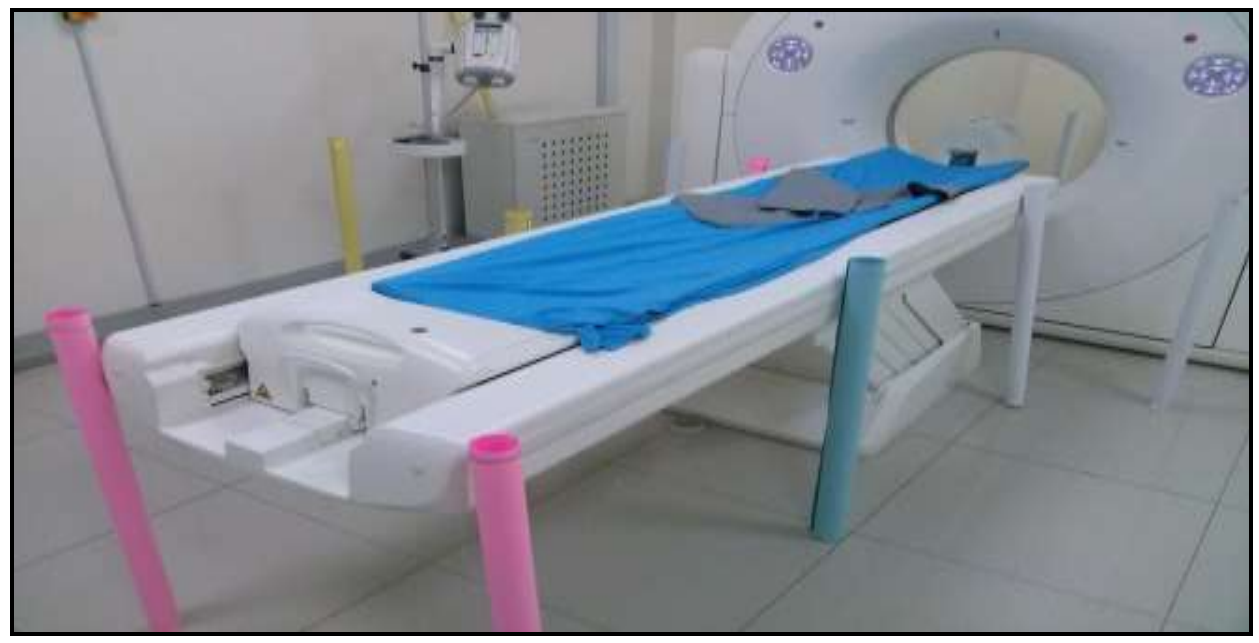

Gambar 4.CT Scan 128 Slicedengankartonberdiri

Penentuan titik pengukuran hamburan sekunde rmenggunakan TLD sebanyak 19 titik secara melingkar, masing-masing titik diberi jarak menjauh yaitu 1 meter dan 1 TLD untuk titik pusat pada gantry. Bagan titik pengukuran dapat disajikan pada Gambar 4.

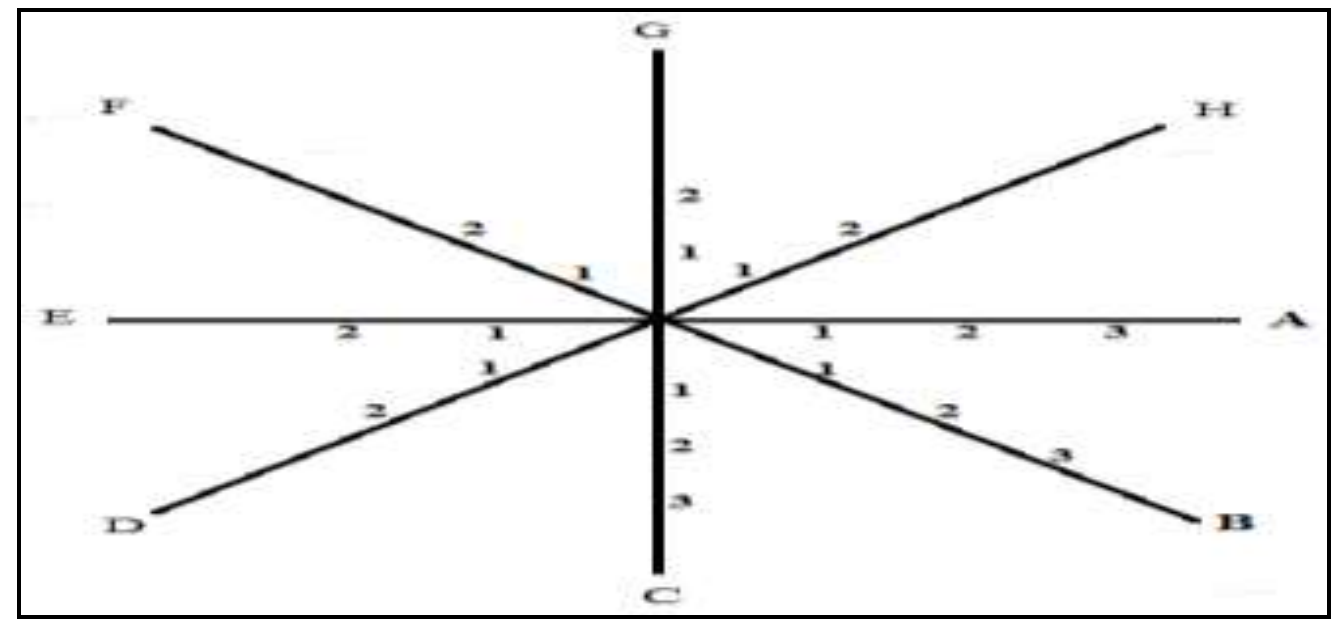

Gambar 4. Bagan penempatan TLD

\section{HASIL DAN PEMBAHASAN}

Hasil dari penelitian yang dilakukan berupa data pengukuran TLD beserta gambaran paparan radiasi hambur Dibawah ini merupakan hasil pengukuran radiasi hambur CT Brain ditunjukkan pada Tabel 1 dibawah ini yang merupakan dosis serap radiasi yang diterima TLD. Didapatkan data pengukuran paparan radiasi hambur dari lintasan pengukuran $\mathrm{A}-\mathrm{H}$, dimana jarak yang digunakan 1 meter, 2 meter, dan 3 meter. Dari lintasan pengukuran D - H 
pada jarak 3 meter tidak bernilai karena tidak terpasang TLD.

Tabel 1. Hasil pengukuran TLD

\begin{tabular}{cccc}
\hline \multirow{2}{*}{ Lintasan Pengukuran } & \multicolumn{3}{c}{ Jarak Paparan Radiasi (mGy) } \\
\cline { 2 - 4 } & 1 Meter & 2 Meter & 3 Meter \\
\hline A & 0.014 & 0.008 & 0.003 \\
B & 0.142 & 0.098 & 0.043 \\
C & 0.182 & 0.138 & 0.075 \\
D & 0.139 & 0.095 & X \\
E & 0.02 & 0.0092 & X \\
F & 0.142 & 0.093 & X \\
G & 0.173 & 0.129 & X \\
H & 0.156 & 0.087 & X \\
\hline Titik Pusat Gantry & \multicolumn{3}{c}{37.02} \\
\hline
\end{tabular}

$\mathrm{X}=$ Tidak dilakukan pengukuran

Untuk membuat pola paparan radiasi hambur seperti pada Table 2, digunakan data pengukuran dari Table1. Dengan menggunakan persamaan $: \frac{D_{1}}{D_{2}}=\frac{r_{2}^{2}}{r_{1}^{2}}$. Dengan diketahui
$\left(D_{1}\right)$ dosis serap, $\left(r_{1}\right)$ jarak pengukuran dan $\left(D_{2}\right)$ nilai tertinggi dari dosis. Maka pola paparan radiasi hambur atau kurva isodosis yang bisa digambarkan seperti pada Gambar 5.

Tabel 2. Data pola paparan radiasi hambur

\begin{tabular}{ccccccccc}
\hline Titik Jarak (meter) & A & B & C & D & E & F & G & H \\
\hline 1 & 0.275 & 0.883 & 1 & 0.873 & 0.33 & 0.883 & 0.974 & 0.921 \\
2 & 0.48 & 1.68 & 2 & 1.659 & 0.51 & 1.641 & 1.931 & 1.587 \\
3 & 0.6 & 2.271 & 3 & X & X & X & X & X \\
\hline
\end{tabular}

$\mathrm{X}=$ Tidak dilakukan pengukuran

Penggunaan variasi jarak 1 meter, 2 meter, dan 3 meter dimaksudkan untuk menganalisa faktor jarak dengan dosis radiasi yang didapat. Hasil pengukuran paparan radiasi hambur dengan titik pusat gantry bernilai 37.02 mGy mendapatkan nilai maksimal pada jarak 1 meter 0,182 mGy, berada di titik C yaitu pada posisi meja pemeriksaan CT Scan dan nilai minimal 0,014 mGy di titik B berada pada posisi sebelah kanan gantry. Pada jarak 2 meter nilai maksimal $0,138 \mathrm{mGy}$ di titik $\mathrm{C}$ berada pada posisi meja pemeriksaan CT Scan dan nilai minimal 0,008 mGydi titik A berada pada posisi sebelah kanan gantry. Pada jarak 3 meter nilai maksimal $0,043 \mathrm{mGy}$ berada pada posisi meja pemeriksaan dan nilai minimal $0,003 \mathrm{mGy}$ berada pada posisi kanan gantry.

Pada variasi jarak 1 meter, 2 meter, 3 meter didapat hasil nilai maksimal yang sama berada pada titik $\mathrm{C}$ yang merupakan meja pemeriksaan. Ini dikarenakan prinsip kerja CT Scan itu sendiri yaitu sumber sinar-x berotasi secara kontinu dengan pasien bertranslasi melalui berkas sinar-x, dimana meja pemeriksaan pasien bergerak selama tabung sinar-x berotasi dan menghasilkan hamburan dari objek sebagai paparan radiasi yang besar. Faktor atenuasi berpengaruh saat berkas sinar-x mengenai objek dan diteruskan ke detektor, maka pada variasi jarak 1 meter, 2 meter, 3 meter didapat hasil nilai minimal yang sama 
berada pada tititk A yang merupakan sisi gantry sebelah kanan.

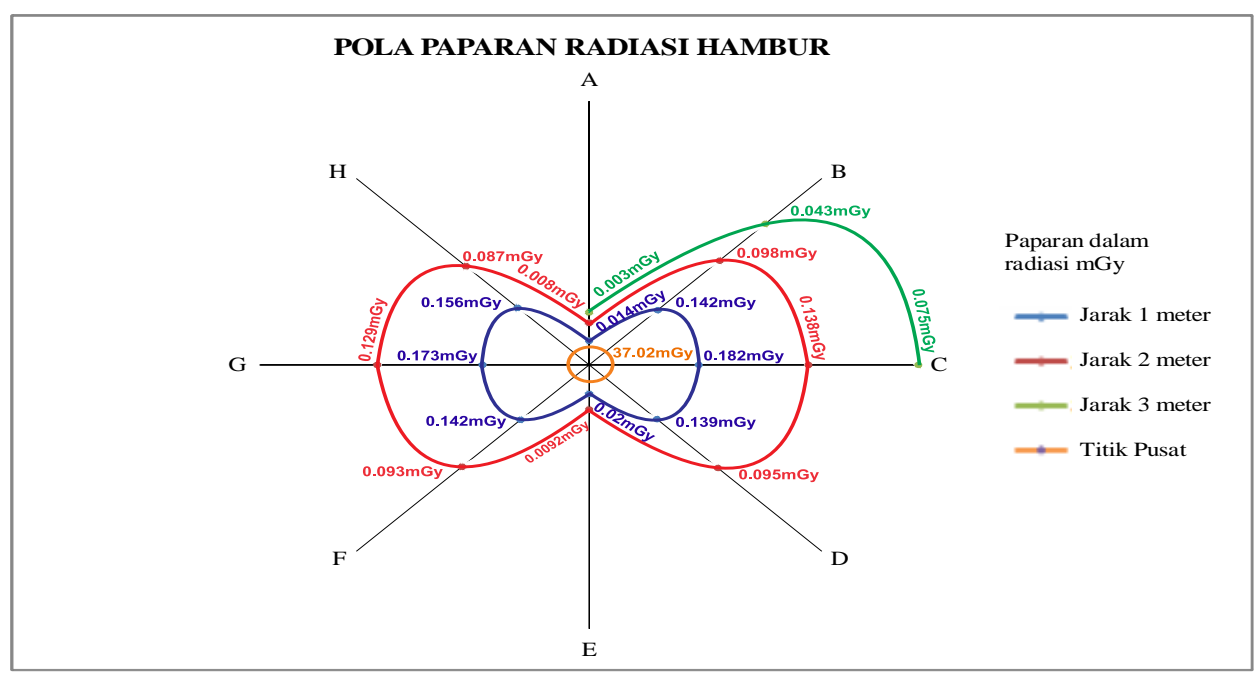

Gambar 5. Kurva isodose radiasi hambur

Dalam Tabel 1. hasil pengukuran setiap jarak 1 meter, 2 meter, 3 meter memperlihatkan perbedaan dosis yang didapatkan. Hasil pengukuran dari jarak 1 meter lebih besar dibandingkan dengan jarak 2 meter dan 3 meter. Ini karena faktor jarak erat kaitannya dengan intensitas radiasi. Intensitas radiasi pada suatu titik akan berkurang berbanding terbalik dengan kuadrat jarak antara titik tersebut dengan sumber radiasi. Untuk membuat pola sebaran menggunakan Tabel 2. dan dibuatkan pola sebaran radiasi hambur terlihat pada Gambar 5. Pola sebaran radiasi hambur yang mempunyai dosis hambur lebih kecil berada disebelah kanan dan kiri gantry dibandingkan posisi di depan dan belakang gantry CT Scan. Paparan radiasi hambur kanan kiri gantry mempunyai dosis kecil karena adanya atenuasi sinar $\mathrm{x}$ terhadap detector. Di Gambar 5. juga terlihat bahwa ketika terjadi pengurangan jarak atau penambahan jarak yang menjauhi sumber radiasi maka paparan dosis radiasi hambur akan berkurang atau menurun. Sebaran maksimal paparan radiasi hambur berada pada jarak 1 meter, dan sebaran minimal berada pada jarak 3 meter. Gambaran pola sebaran radiasi hambur bermanfaat untuk mengantisipasi dan mengurangi secara signifikan radiasi hambur pada pemeriksaan CT Scan Brain. Upaya tersebut dapat berupa memaksimalkan jarak dari gantry dan menggunakan pakaian pelindung radiasi.

\section{KESIMPULAN}

Hasil pengukuran sebaran radiasi hambur menggunakan CT Scan 128 slice pada pemeriksaan CT Brain menunjukkan adanya perbedaan nilai sebaran radiasi hambur di setiap jarak pengukuran 1 meter, 2 meter, dan 3 meter dari titik pusat gantry. Semakin jauh jarak pengukuran nilai sebaran radiasi hambur semakin kecil. Pola sebaran menunjuk kan bahwa jarak berpengaruh terhadap intensitas radiasi. Semakin dekat dengan sumber radiasi, intensita sradiasi semakin besar, sedangkan semakin jauh dari sumber radiasi intensitas radiasi semakin kecil.

Paparan radiasi hambur pada pemeriksaan CT Brain dengan pesawat CT 
Scan 128 slice merk Siemens milik Rumah Sakit Islam Cempaka Putihdengan titikpusa tpengukuran di gantry bernilai $37.02 \mathrm{mGy}$ mempunyai nilai minimal di titik kanan dan kiri gantry pada jarak 1 meter dengan nilai 0.014 mGy dan $0.02 \mathrm{mGy}$, pada jarak 2 meter dengan nilai $0.008 \mathrm{mGy}$ dan $0.0092 \mathrm{mGy}$, dan pada jarak 3 meter dengan nilai 0.003 mGy. Nilai titik maksima lpada posisi depan dan belakang gantry pada jarak 1 meter dengan nilai 0.173 mGy dan $0.182 \mathrm{mGy}$, pada jarak 2 meter dengan nilai $0.129 \mathrm{mGy}$ dan $0.138 \mathrm{mGy}$, dan pada jarak 3 meter dengan nilai 0.075 mGy.

\section{DAFTAR KEPUSTAKAAN}

AAPM report no.25. 1988. Protocols for the radiation safety surveys of the diagnostic radiological equipment American Association of Physicists in Medicine by the American Institute of Physics.

Stewart CB. 2000. computed tomography Book Essentials of Medical Imaging Series Edition 1. McGraw-Hill Medical.

Syahria, Evi S dan K Sofjan. 2012. Pembuatan kurva isodosis paparan radiasi di ruang pemeriksaan intalasi radiologi rsud kabupaten kolaka-sulawesi tenggara Jurnal berkala fisika vol.15 (4): 123-132.

Togap M. 2006. Proteksi radiasi dalam radiologi intervensional Makalah Seminar Keselamatan Nuklir 2-3 Agustus 2000.

Adi DNW. 2010. Analisis sebaran radiasi hambur dari pasien pada pesawat fluoroskopi dengan metode montecarlo dan pengukuran. Tesis Universitas Indonesia Fakultas Matematika dan Ilmu Pengetahuan Alam Program Magister Fisika Kekhususan Fisika Medis.
Buzug TM. 2008. Computer Tomography From Photon Statistics to Modern ConeBeam CT. Berlin Heidelberg: SpringerVerlag.

Beiser A. 1991. KonsepFisika Modern, Edisi 3, Terjemahan The HouwLiong. Jakarta: Erlangga.

SyahriadkkPembuatanKurvaIsodosis 132.

Plaats VD, GJ. 1972. Medical X-Ray Technique, Third Revised and Erlarged Edition.

Meredith WJ and Massey JB. 1977. Fundamental Physics of Radiology. Bristol: John Wright and Sons.

Akhadi M. 2000. Dasar-Dasar Proteksi Radiasi. Edisi I. Jakarta: Rineka Cipta.

Wiryosimin S. 1999. Mengenal Asas Proteksi Radisi. Bandung : ITB Bandung.

IAEA. 2005. Training Material on Radiation Protection in Diagnostic and Interventional Radiology,IAEA, Vienna.

Diagnostic X-Ray equipment compliance testing: workbook 1-Mobile Radiographic Equipment, Radiological Council of Western Australia,ISBN 09775570-1-4, Nedlands Western Australia, 2006

Wardhana WA. 2007. Teknologi Nuklir : Proteksi Radiasi dan Aplikasinya. Yogyakarta : C.V ANDI. 